NOVAS TENDÊNCIAS NO ENSINO E NA PRÁTICA DA ENFERMAGEM

Circe de Melo Ribeiro*

No editorial da Revista Brasileira de Estudos Pedagógicos, janeiro de 1969, há uma referência à crescente preo cupaçäo de melhor utilizar tôdas as virtualidades do homem para melhor atender às necessidades sociais, considerando o fator hu mano como o leit motiv dos planos de desenvolvimento. Coloca ainda o problema da Educaçāo Permanente, que é tratado em to dos os artigos daquềe número, como uma necessidade do desen volvimento e do próprio homem, para que êste se torne beneficiá rio de sua cultura e propulsor do seu progresso, além de constrú tor de uma nova civilização.

Os ilustres pedagogos, autores de vários artigos daquela Revista, tratam do assunto (construção de uma nova civili zação) filosófica e pràticamente, porém, todos nós estamos tam bém sentindo os princípios do fim de uma civilizaçāo e início de uma outra, mais promissora, mais coerente, com maior uso da capacidade racional em têrmos de bem comum. Talvez êste seja nosso mais ardente desejo.

As novas geraçōes, todavia, para colimar tais objetivos terão que ser mais alertadas quanto aos problemas que emperram nosso desenvolvimento e quanto à valorizaçāo do pro cesso educativo, que deverá condicionar mudança de atitude e abertura de novas frentes de ataque ao tradicionalismo exagerado e ao comodismo estabelecido pelas geraçōes passadas.

Acreditamos que somos uma geraçāo intermediá ria, esmagada por inúmeros problemas não resolvidos e repleta de esperanças de um mundo melhor.

\footnotetext{
* Professôra Assistente de Administração aplicada à Enfermagem.
} 
Na Enfermagem, que ainda não atingiu sua fase de pleno desenvolvimento, mas que está seguramente a caminho dela, sentimos da mesma forma: defrontamos muitos probleñas e obstáculos, sabemos que muita coisa há para ser feita em sene fício do bem estar social e temos esperança de que, um dia, a as sistência de enfermagem não só será prestada a tôda a popüação. mas como o melhor pessoal, preparado e integrado na filosofia di desenvolvimento que, se traduzido, nada mais significaria que i bem geral.

Dualismo na enfermagem

O ensino e a prática da Enfermagem são ùuis as pectos de um todo que não pode ser dividido; constituem a.pens.s seus dois têrmos correlativos. Todavia, a grande queixa de nos: sas enfermeiras é que a teoria nem sempre se aplica na prátic profissional; os docentes de enfermagem são rotulados de itteór:cos", fora da realidade, e não capazes de executar aquilo qic ẹ: sinam. Por outro lado, o trabalho das enfermeiras de campo ë classificado como "rotineiro" e a queixa dos docentes é que não $\dot{c}$ possível melhorar o ensino sem boa qualidade do cuidado dc enfer magem.

Näo vale a pena discutir ou examinar aqui as $r$ zōes históricas que levaram a êste estado de coisas; tôdas nós t: mos algum conhecimento do assunto. Atualmente talvez falie a vontade de admitir que o problema existe, e talvez também fäte, de maneira geral, a consciência das graves consequências pià̃a à enfermagem como profissão: desprestígio e vulnerabilidaủe, caị sados pela situação conflitiva ensino/prática.

A conscientização do problema poderá sér fácil i tada se trouxermos alguns elementos para discussāo, com o ojjeti vo se conseguirmos a devida correlaçāo entre as partes.

Virginia Henderson nos diz que a funçāo da en fermeira consiste, antes de tudo, em ajudar o indivíduo, dserite ou não, naquelas atividades que contribuem para manter ou recupe 
rar a saúde e, ainda, que o esfôrço da enfermeira deve cer no sentido de gradativamente tornar 0 indivíduo independente de sua ajuda.

No conceito que é adotado pelo Conselho Interna cional de Enfermeiras (ICN) está implícita a funçāo educativa é preventiva da enfermeira.

O "Quinto Informe do Comité de Expertns de l三. OMS em Enfermeria" traz a definiçāo que o Conselho Internacie!: nal de Enfermeiras, órgão assessor da OMS nos assuntos de $€$ ה fermagem, deu à enfermeira: "a pessoa que completa um prugr:: tât đe građuaçăo em enfermagem e está qualificada e autcrizada, no País, a prestar serviços de maior responsabilidade para a prö moção da saúde, prevenção da doença e cuidados do indivídıo dio ente".

Êstes dois conceitos definem tanto os oijetivis das Escolas de Enfermagem - formar enfermeiras capazes mo de serviços de Enfermagem - prestar assistência cornpleté de enfermagem aos indivíduos doentes ou sãos - . Não deveria, portanto, haver conflito algum entre ensino e exercício, embor. enfoquem inicialmente dois objetivos diferentes, como pricridade.

Se considerarmos, ainda, as novas tendências da formação profissional, segundo as quais o campo deve favor: cer o aprendizado e o ensino deve se processar, cada vez mais, fo ra das salas de aula, vamos verificar que, ao campo de aprericios gem, se está dando muito mais importância hoje, que no fasssadr, e que aos educadores cabe maior responsabilidade e maior atıa çāo no campo.

Segundo escreve Durmeval Trigueiro na citain Revista Brasileira de Estudos Pedagógicos "há um nítido proce so de convergência de tôdas as técnicas sociais, como última eta pa da sociedade industrial, superando dualismo que ela própria exacerbara (sobretudo entre trabalho e educação)". Diz êle "Tôda açāo para tôda a educação. Tôda educaçāo para tôda açāo". Ao Homo Sapiens e Homo Faber a humanidade deu uma identidade só - Homem. 
Considerando ainda que a enfermagem está en tre as profissōes liberais, podemos acrescentar como elemento de juízo na questão, os critérios para definir uma profissão libe ral, propostos por Flexner em 1910.

1. profissāo liberal envolve operaçōes intelectuais com gran de responsabilidade individual;

2. a essência da profissão liberal é retirada da ciência e do processo contínuo de aprendizado e experiéncia;

3. os elementos essenciais sāo desenvolvidos para um fim prático e definido;

4. os profissionais liberais devem dominar as técnicas edu cacionais;

5. os profissionais liberais tendem a organizar-se por açāo coletiva, voluntária;

6. os profissionais liberais tornam-se cada vez mais altruís tas.

A éstes podemos acrescentar outros critérios propostos por R. Tawney em 1921 e apresentados por Marie Jaho da em 1961 (6):

7. a consecuçāo dos objetivos é mais importante que a com pensação econômica;

8. os profissionais liberais realizam seu trabalho de acôrdo com certas normas e regulamentos, cujo propósito é de fender o público e o profissional liberal que o serve.

Ensino e exercício correlacionam-se, nestes cri térios, de maneira perfeita.

Implicaçōes gerais

Estes poucos elementos nos levam a admitir que se há conflitos entre o ensino e a prática da enfermagem, todo es fôrço possível deverá ser feito em função de reduzí-lo ou anula- 
10, pois nāo sāo desejados pela sociedade. A enfermagem é uma profissāo nascente no Brasil. Nossa tarefa, como profissionais, é produzir serviços necessários à sobrevivência, é produzir saú de.

Segundo C.G. Melo os países só contarão com pessoal de enfermagem em qualidade e quantidade para atender às suas necessidades quando atingirem elevados níveis de desenvolvi mento econômico.

Ainda segundo o mesmo médico-sociólogo, são legítimas as pretensões da enfermagem (já conquistadas) como profissāo liberal, em participaçāo maior na renda nacional. O que não devemos esquecer, diz C.G. Melo, é que os altos padrōes téc nicos e elevados níveis quantitativos dependem do desenvolvimen to econômico de uma sociedade com altos níveis de vida.

Gozamos hoje, portanto, de um privilégio, esta mos no nível técnico-científico e participamos mais da renda na cional, apesar do País nāo ter atingido completo desenvolvimento. O.ônus dêsse privilégio é o dever de assumir maiores responsabi lidade no desenvolvimento do País.

Estaremos também cumprindo nosso dever de contribuir para o desenvolvimento econômico social ? Se não o fi zemos, tudo que já conquistámos sofrerá estagnaçāo e até mesmo deterioração.

Se nossos esforços não se concentrarem no que já está definido, oferecendo à sociedade aquilo que já conhece e espera de nós, e se nāo estamos preparados para promover o de senvolvimento da profissão, enfrentaremos, inclusive, o proble ma da interferência de outras profissões nas decisões que nos cá bem de direito, pois que de fato não exercemos o poder.

De direito e de fato sāo expressōes jurídicas muito convenientes na colocação da problemática da enfermagem. O direito de decidir sobre enfermagem é nosso há algum tempo, porém, de fato, isto nāo acontece quando o grupo de enfermeiras de uma instituiçāo é vacilante ou sem liderança. 
Diante dêstes argumentos, seria demasiado exi gir que cada enfermeira analisasse a situação e procurasse adô $\operatorname{tar}$ novas atitudes frente à exigência que a profissão e a scciedade nos fazem? Seria lícito o exercício de enfermagem em tërmos individuais, procurando a enfermeira, confôrto, comodidade, sem enfrentar os problemas que a classe enfrenta? Êstes são Fontco importantes para a profissão e os profissionais, queiram ou nã-. são parte dela. E, portanto, questão de sobrevivência.

Tanto às Escolas como aos Serviços de Enferr: gem cabe identica responsabilidade de oferecer às estudartis $\approx$ en. fermeiras melhores condiçōes de aprendizado e exercício; portál? to, a coordenação entre ambos é uma exigência. Educação e tro balho preparam o estudante para a totalidade de ação, couio um ser único. Está presente o princípio da conversibilidade relativà. O serviço converte-se em escola, utilizando a educação, e a. escr. la converte-se em consumidor, utilizando a prática.

A harmonia entre educação e prática irá iavore cer o desenvolvimento da profissāo e do profissional, dando a êst maiores possibilidades de contribuir para o progresso de Paíi. Voltamos a insistir: as Escolas e os Serviços de Enfermaüem têm muito a oferecer um ao outro, e têm o dever de fazế-1n. $\mathrm{N} s$ nhuma escola sobrevive sem relaçāo a um contexto social, seis aplicação prática dos conhecimentos teóricos que difunde, $\epsilon$ ne: nhum serviço sobrevive sem alimentar-se continuadamente de nó. vos conhecimentos e da renovação de métodos. O constante "reeúback" dependerá do entrosamento educação-trabalho.

\section{Educzçāo Contínua}

O mundo em constante mudança condicic:ua ta ne cessidade de preparaçāo permanente para fazer frente às novas necessidades criadas e à nova tecnologia.

Seguindo a mesma linha de raciocínio, o que cha mamos de Educaçāo em Serviço passa a fazer parte da Educaçāo Permanente, como estratégia cultural a serviço de uma polititica 
definida de Recursos Humanos, dentro dos planos de desenvolvi mento. Por isso, na Enfermagem, preferimos denominá-la Edu cação Contínua ao invés de Educação em Serviço, para significar o processo de desenvolvimento-individual integral, ampliando o conceito e o sentido da expressão, projetando-os além da necessi dade sentida pela instituição.

O processo, sistema ou estratégio da Educação Contínua na Enfermagem, atinge todo o pessoal de enfermagem e em especial a enfermeira, como profissional liberal, que assume maior responsabilidade.

Na realidade todo o indivíduo, mesmo que não tenha recebido educaçāo formal, sofre o processo educativo atra vés das instituiçōes sociais, famúlia e igreja, e dos grupos da co munidade ou grupos de trabalho. Se lhes oferecemos um progra ma de treinamento em serviço, por exemplo, estamos continuando um processo educativo já iniciado.

Para impregnar os programas de treinamento ou preparação de pessoal de enfermagem com êste sentido mais amplo, necessário se faz que seus programadores tomem conheci mento da realidade social que os cerca, além das portas de insti tuiçāo.

A Educaçāo Contínua prepara o indivíduo para o diálogo e oferece instrumentos para aumentar sua capacidade ana lítica, tanto em relação a si mesmo como ao grupo a que pertence e à situaçāo nacional. Portanto, às diretoras de Serviços de En fermagem e às assistentes de direção, responsáveis pela prepara ção ou treinamento de pessoal; cabe muito maior responsabilida de; lembraríamos ainda que uma das mudanças que o desenvolvi mento da tecnologia trouxe foi considerar como escola o campo de trabalho dos profissionais em geral. As escolas e universida des não mais pretendem nem têm como objetivo preparar apenąs o profissional, mas sim o homęm; e também não oferece à socie dade um produto acabado. A educação é um processo contínuo e todos são responsáveis por ela. 
O pessoal de enfermagem hospitalar no Brasil era (1957), e ainda $\dot{e}$, constituído de $70,8 \%$ de atendentes, $19,3 \%$ de auxiliares de enfermagem e 9,9\% de enfermeiras; portanto, os atendentes executavam e executam a maior parte dos cuidados de enfermagem.

Mesmo em hospitais universitários, até bem pou cos anos, a situaçāo era aquela, com o agravamento de que o pes soal (principalmente o atendente) nāo era sequer treinado.

Quantas vêzes uma enfermeira escrevia ordem de enfermagem sem ao menos ter discutido com o seu pessoal $(70,8 \%$ de atendentes) sobre o diagnóstico médico do paciente, suas necessidades, as prioridades do cuidado ou sôbre as razōes de tais ordens?

O resultado era a repetição exaustiva da ordem, a não cooperação do pessoal e o prejuízo para o paciente que não era devidamente cuidado. Para a enfermeira o resultado era tam bém negativo: desprestígio, conflito com os médicos e existência de prescriçōes médicas de cuidados físicos de enfermagem tais co mo: banho, mudança de decúbito etc.

Quantas vêzes nāo encontramos, numa unidade de internação com 40 pacientes, 40 prescriçōes de "contrôle hídri co", apenas para dar trabalho à enfermagem, numa agressāo mu da à baixa qualidade da assistência de enfermagem ? Ou então o próprio médico fazendo o contrôle hídrico nos pacientes nos pro gramas de pesquisas, porque não confia na enfermagem ?

Que as enfermeiras deixem ou não de se respon sabilizar por estes tipos de contrôle, nas pesquisas médicas, dis cutindo racionalmente com o grupo médico e encontrando uma so lução, é uma coisa; porém, que deixem de fazê-1o porque foram consideradas incompetentes é outra coisa muito diferente.

O raciocínio lógico deve ser desenvolvido nas es tudantes de enfermagem e nas enfermeiras, paralelamente ao aprendizado técnico, exatamente para permitir que tomem deci sōes mais acertadas. 
O processo educativo deve continuar no campo de trabalho. Neste ponto nevrálgico reside a maior falha dos pro gramas de Educação Contínua. As enfermeiras são as que menos participam como sujeito do processo e principalmente de estraté gia cultural.

Precisamos de líderes na enfermagem. Quem as está preparando? Como estão sendo preparadas ? Quantas bi bliotecas de enfermagem já foram organizadas no Serviço de En fermagem? Quantos serviços ou setores de Educaçāo Contínua se organizam, de forma completamente organizada, com pouca participação e cooperação das enfermeiras chefes? Quantas su pervisoras estão preparadas nesses programas? Onde está o êr ro com as supervisoras, enfermeiras, ou com as responsáveis pe los programas? E o que procuraremos esclarecer mais adiante.

Um fato que já foi constatado em vários servi ços de enfermagem, no Brasil e no exterior, é que a frequência voluntária das enfermeiras aos programas de Educação Contínua é muito raxa e quie a compulsoriedade de participaçāo nāo agrada aos responsáveis pelos programas, nem às enfermeiras. Tais fa tos são sinais evidentes de mau planejamento, pois acontece o que näo deveria acontecer.

Não deveria acontecer porque:

1. o princípio básico dos programas de Educação Contínua é a necessidade social de promoçāo e de desenvolvimento que todos os indivíduos manifestam;

2. a era é de transformação social; o que se aceitava no passado pode nāo se aceitar hoje, e vice-versa; novos con ceitos aparecem com implicaçōes para o ensino e trabá 1ho;

3. a ciência e a tecnologia, em seu progresso assombroso, obrigam todos a realizar esforços para manter ou acele rar o processo de desenvolvimento ou pelo menos para não provocar sua deterioração; 
4. o conteúdo do ensino nas escolas de enfermagem passa por revisões contínuas para acompanhar o progresso em geral;

5. a enfermagem é profissāo nascente, carente de líderes.

Tôdas estas razōes sāo fatôres muito interlił€̨ dos e dêles se deduz a necessidade da atualizaçāo de conhecime: tos e dos métodos de trabalho e do preparo de líderes. As institui çōes de saúde são responsáveis por uma certa sistematizaçä̀ cia Educaçāo Permanente para todo o seu pessoal e os Serviços de E: fermagem para o pessoal de enfermagem e, de modo especis!, ffí. ra suas enfermeiras.

A necessidade de colocar maior ênfase na Fiuca çāo Contínua para enfermeiras é óbvia: elas formam o grı̣jo cí decisōes na enfermagem. Não adiantará preparar e atualizar : pessoal auxuliar se os profissionais, que os lideram e supervisio nam, nāo estiverem bem preparados.

Fases da Programação

A Educação Contínua num Serviço de Enferma gem comporta várias fases na sua programação, com objetivos $€ \underline{\underline{E}}$ pecíficos, porém, não se pode esquecer de relacionar cada progra ma com o contexto social no qual o serviço ou a instituiçāo estä: inseridos.

Os Serviços de Enfermagem têm grande respon sabilidade na aplicação da ciência administrativa, pois, através de uma boa organizaçāo é que poderá alcançar seu objetivo prircipa! ou único: a assistência integral de enfermagem aos pacientes ou indivíduos sãos. Isto significa atuar nos programas de promóçã, manutenção e recuperação da saúde, como parte de uma equipe multidisciplinar, segundo as necessidades de cada indivídun e de acôrdo com as metas propostas para elevar o nível de saúde popu lação.

Os programas de educação visam tornar o pesso al de enfermagem cada vez mais capaz de colaborar com a organi zação, para que sua finalidade seja alcançada. 
Fundem-se entāo os processos administrativos e educativos. A educação é um meio de melhorar a administra ção, e a ciência administrativa permite a organizaçāo da educa ção. A falta de preparo do pessoal pode quebrar uqualquer siste ma administrativo e uma organização pobre pode deteriorar qual quer sistema educativo.

Não basta, porém, rotular alguns programas pa ra se ter a Educação Contínua no serviço; é preciso que cada pro grama seja parte de um plano e que seu valor intrínseco seja valo rizado a aceito por todos; que sirva à instituição, servindo pri meiro ao indivíduo.

\section{Orientação}

Os programas da fáse de Orientação têm como objetivo introduzir e colocar um nôvo empregado no serviço ou um antigo empregado num cargo (ou função) nôvo. Segnifica tornálo conhecedor das características específicas de seu cargo e das condiçōes para exercê-lo bem, das responsabilidades e direitos que terá, das expectativas da instituição e da comunidade.

Para um novo empregado, deve constar do pro grama de Orientação tôda a informação possível sôbre meio ambí ente, organização, serviços e interrelaçōes, pessoal (regulamen tos e normas), funçōes e etc.

Nesta fase inicia-se o julgamento que o pessoal nôvo faz sôbre a instituição, e que terá reflexos nas suas reaçōes futuras e no seu grau de motivação para os próximos programas e próximos anos de trabalho. E importante preparar o clima da re cepção para torná-lo o mais favcrável possível ao programa de orientação envolver o nôvo empregado com a instituição (mística da administração e da educação) de forma que se sinta uma parte dela.

Os métodos variam de acôrdo com a situaçāo e recursos. Os programas e o tempo variam de acôrdo com o nível de decisöes dos cargos a serem preenchidos. O importante é que 
todos, independentemente da categoria a que pertencem, sejam ori entados e que, como ponto fundamental para as relaçōes humanas, sejam tomadas em consideraçāo as habilidades já adquiridas. Não se pode apagar uma experiência simplesmente ignorando-a.

\section{Treinamento}

Os programas desta fase têm.como objetivos ha bilitar os noves empregados (ou antigos empregados para cargos novos) a executarem as atividades exigidas para o cargo, não ape nas desenvolvendo habilidades manuais, porém, também as men tais; e reforçar a fase de orientação no sentido de integrar me lhor o indivíduo na organização, a serviço da comunidade.

Geralmente, pouca atenção se dá nesta fase ao aspecto da atitude do pessoal diante do problema saúde; todavia, esta é de importância capital na Educação Contínua em Enferma gem. Se fossemos dar exemplo nada melhor que o capítulo da hi giene pessoal, dos hábitos de higiene.

Vale ressaltar a necessidade de programas par tindo do conhecido para o desconhecido, fazendo revisão dos conhe cimentos de cada indivíduo, nāo só para servir de base a um nôvo aprendizado como para analisar e corrigir as falhas decorrentes de um aprendizado anterior.

O conteúdo dos programas será variável de acôr do com as funçōes e técnicas que o pessoal deve executar na orga nização; quanto à duração será considerado o tempo necessário para que a assimilação se produza.

O local será o próprio do trabalho, (situaçāo re al), porém, que não interfira na segurança dos pacientes ou clien tes.

De forma geral considera-se sujeito dos progra mas de treinamento apenas o atendente; todavia, o pessoal de tô das as categorias de enfermagem deve receber certo tipo de trei namento para ajustá-lo ès técnicas, normas e planos da institui çāo. 
E essencial que êstes programas sejam avalia dos constantemente e que a supervisão seja contínua e direta. A quêles que não se desenvolvem bem deverão passar por nôvo tré namento antes da colocaçāo definitiva no cargo ou na funçāo.

3. Atualização

Ampliar os conhecimentos e habilidades do pes soal do Serviço são os objetivos dos programas nesta fase, além de: ajudá-lo a conservar os conhecimentos já adquiridos, desen volver o pensamento crítico e aperfeiçoar a atuaçāo. A finalidade última é a utilização plena das potencialidades de cada um para melhorar a qualidade da assistência integral de enfermagem e ca pacitar o pessoal para análise, a crítica e a tomada de decisão.

Gostaríamos de fazer alguns comentários sôbre - que temos visto no País e no exterior. A maioria dos progra mas são executados de forma centralizada. As diretoras de Servi ço de Enfermagem ou Assistentes de Educaçāo em Serviço prepa ram os programas e os executam, desrespeitando a autoridade das enfermeiras, responsáveis diretas pelo pessoal, e desrespei tando os problemas particulares de cada setor ou unidade de traba Iho. A participaçāo do pessoal nāo motivado para êstes progra mas é quase nula e os resultados nem sempre são avaliados.

Temos visto alguns excelentes programas de atualização nos serviços ou unidades, que funcionam na base do trabalho em equipe. Todo o pessoal da unidade participa daquilo que é vital para a enfermagem - o planejamento individualizado de cuidado. A medida que novos pacientes ou clientes são coloca dos na unidade ou setor de trabalho, seus problemas e necessida des são examinados por todo o grupo, liderado pela enfermeira, maior responsável pelo aspecto científico do problema.

Esta é a situação ĩdeal para a Educação Contínua; o grupo se desenvolve, sua capacidade de diálogo se amplia, sua segurança é maior seu trabalho é de melhor qualidade. Poderá 
haver também uma programaçāo especial para cada grupo, sob a responsabilidade das enfermeiras do setor ou unidade ou da assis tente em Educaçāo Contínua.

Os novos equipamentos, técnicas, rotinas $:$ tra tamentes poderão ou não ser tratados nos programas ceríraliza dos, por categoria, com alguma participação das enfermeirałs che fes.

Quanto às necessidades sentidas pelo grupo, $\mathrm{p} \underline{\text { S }}$ rém, não diretamente relacionado com o trabalho nas unjdades, poderāo ser tratadas em programas por categoria, centralizaios ou descentralizados. Em qualquer dos casos já apontados os mé todos ativos devem ser proferidos. Em qualquer tipo de programa deve ser feita correlação com os problemas da comunidade, assim como a colocação dos problemas do desenvolvimento econûmico social.

Com a descentralização dos programas as enfe: meiras chefes e supervisoras (ou assistente) assumem maior res ponsabilidade para com sua própria atualização. Isto, toravia, não impede que para êstes dois grupos sejam preparados progra mas de atualização centralizados, de acôrdo com as necessidades sentidas (pelo grupo) ou para cobrir assuntos novos e de interêsse. geral.

\section{Liderança e Preparo para Chefia}

Esta fase existe exclusivamente para enfermei ras que são as profissionais do grupo de liderança e que prodem ocupar cargos de chefia.

Raríssimos são os serviços que mantêm tal tipo de programa, embora sejam, pela lógica, os programas oirigató rios.

Seminários, simpósios, grupos de discussão, conferência de grupo, painéis seriam os métodos indicados. Os as suntos que cabem nestes programas são muitos; citaremos alguns: administração de pessoal, administraçāo de unidade ou setos. de trabalho, incidente adnuinistrativo, incidente técnico, planejamen 
to e metas de saúde, planejamento de cuidados individualizados, su pervisāo, educaçāo contínua, programação científica,estudos e pes quisa, técnica de orçamento, auditoria de Serviço de Enferuageın, preparaçāo de escriturária de unidade, especializaçāo clínica, in tegraçāo ensino-exercício, métodos didáticos, entrevista, interven çāo de enfermagem, etc.

A qualidade do pessoal é um reflexo de qualida de do dirigente. Assim é conveniente preparar aquelas que vão ocupar cargos de direção para ter boa enfermagem através do pes soal liderado por ela.

Há vários tipos de abordagem para determinar a necessidade e/ou o conteúdo de programa de liderança e preparc para chefia:

1. avaliaçāo de situaçāo pelos relatórios, dados estatísticos, incidentes, etc.;

2. análise da situaçāo: problemas semelhantes e frequertes:

3. planos de promoção;

4. questionário às enfermeiras.

A condição básica para o êxito dos programas $\dot{e}$ a participaçāo efetiva das enfermeiras no seu planejamento, exécuçāo e avaliaçāo.

\section{Princípios de Planejamento de Programas}

Os princípios de investigação, ordem e realida. de sāo comuns ao ensino e exercício de uma profissão e de impor: tância maior que os demais princípios.

No ensino, o princípio da investigaçāo deve nor tear todo o processo de planejamento, programação do currículo e das atividades curriculares. O método científico deve ser siste màticamente utilizado por docentes e discentes para qualquer pro blema que the seja proposto. No exercício, que é uma exterisão do ensino, aplica-se a mesma exigência. 
O princípio da ordem deve nortear a coordena ção e a organização do ensino. O contrôle da eficiência depende da aplicação do princípio da ordem ao processo da coordenação e organização. Isto também é verdade para o exercício.

O princípio da realidade deve encaminhar todo o processo de execução e liderança, afetando os dois campos ensi no e exercício de "per si", indo até a intercorrelação perfeita en tre ambos.

A programação das diferentes áreas ou fases da Educação Contínua deve respeitar os princípios administrativos e de educação:

1. os objetivos devem ser bem definidos, possíveis e reais;

2. as prioridades devem ser atendidas em planos e longo e curto prazo;

3. a participação do pessoal no programa deve ser efetiva;

4. os planos e programas devem ser flexíveis e revisados periòdicamente;

5. os temas e experiências práticas devem estar perfeita mente relacionados com os objetivos que se pretende al cançar;

6. as comunicaçōes sobre os programas devem ser as mais amplas possíveis;

7. a administraçāo deve conhecer e apoiar os planos de edu caçāo do Serviço de Enfermagem;

8. qualquer programa executado deve ser seguido de uma avaliação da qual todos os participantes devem tomar co nhecimento;

9. os êrros ou falhas devem ser corrigidos imediatamente;

10. os programas devem desenvolver-se sem prejudicar os cuidados aos pacientes;

11. os responsáveis devem estar bem preparados para o ensi no; 
12. 0 m métodos de ensino devem ser ativos e o material didá tico adequado ao nível de cada grupo e de suas necessi dades;

13. cada plano deve estar relacionado com o planejamento global de educaçāo do Serviço de Enfermagem e sob o controle de uma Assistente de Educação ou da própria Diretoria do Serviço;

14. deve haver equilibrio entre 08 aspectos técnicos (conheci mento e habilidades) e aqueles referentes a atitudes, va lôres humanos e interrelaçōes (concuta) em cada progra maçāo.

\section{Sumário}

Como objetivo mediato ou imediato, a assistẹn cia integral de enfermagem é responsabilidade tanto das Escolas como dos Serviços de Enfermagem.

A enfermeira, como profissional liberal, é pre parada para colocar a ciência e o método científico a serviço dé indivíduos doentes ou sāos.

A utilização do método científico deve ser do do mínio da enfermeira, tanto para os assuntos administrativos como para os técnicos ou educacionais:

A atuaçāo da enfermeira está enquadrada na equi pe de saúde para a elevação dos níveis de saúde da sociedade; por tanto, ela é participante ativa do processo de desenvolvimento eco nômicosocial. Saúde é apenas um dos setôres do bem estar social.

O ensino e a prática da enfermagem, como têr mos correlativos do mesmo problema, estāo muito interligados, exigindo cooperaçāo mútua, contínua entre educadores e pessoal dos serviços de enfermagem.

A conceituaçāo moderna da Educaçāo em Servi ço como Educaçāo Contínua amplia, nāo só a programaçāo relació aada com seus objetivos, mas também a responsabilidade da enfer meira. 
O grupo de direção deve ser preparado para a $1 \underline{1}$ derança. A motivação e o respeito pelo trabalho sāo comunicados ao pessoal em linha descendente, além do exemplo e capacidade de trabalho.

Nenhum programa de Educação Contínua, por mais cientificamente élaborado que seja, resiste a organizaçāo e administraçāo deficientes.

Os programas de Educação Contínua que não obe decem aos princípios didáticos e administrativos apenas preen chem um vasio na atividade de uma enfermeira.

"O preço não justifica o disperdício de tempo e recursos".

$\underline{\text { Referências Bibliográficas }}$

1 - ASSOCIAÇĀO BRASILEIRA DE ENFERMAGEM - Centro de le vantamento de recursos e necessidades de enfermagem. S.1. p., Associaçāo Brasileira de Enfermagem, s.d. 5 par tes.

2 - EDUCAÇÃO permanente. Revista Brasileira de Estudos Pe dagógicos, 50 (113) : jan-mar. 1969.

3 - FLEXNER, A. - Medical education in United States. New York, Cornegie Foundation for the Advancemant of Teochug, 1910.

4 - HAMELIN, I. - Guide for inservice education of nursing personnel. Geneva, World Health Organization, 1967.

5 - HENDERSON, V. - Princípios básicos sôbre cuidados de enfer magem. Rio de Janeiro, Associação Brasileira de Enfer magem, 1958.

6 - JAHODA, M. - A social psycholist views nursing as a profes sion. American Journal of Nursing, 61 (7):52-56, jul. 1961.

7 - MELO, C.G. - A enfermagem como profissāo na atual conjuntu ra social. Revista Paulista de Hospitais, 11(6):25-26, jun. 1963. 
8 - MILLER, M. A. - Inservice education for hospital nursing per sonnel. Chicago, NLNE, 1958.

9 - ORGANIZACIÓN MUNDIAL DE LA SALUD - Comité de exper tos de la OMS en enfermería. Geneva, OMS, 1966.

RIBEIRO, C. M. - Novas tendências no ensino e na prática da enfer magem. Rev. da Esc. de Enf. da USP 4 生 (1-2): 21-39;mar-set. 18\%. 